\title{
Communication
}

\section{Supercritical Processing as a Route to High Internal Surface Areas and Permanent Microporosity in Metal\#Organic Framework Materials}

Andrew P. Nelson, Omar K. Farha, Karen L. Mulfort, and Joseph T. Hupp

J. Am. Chem. Soc., 2009, 131 (2), 458-460• DOI: 10.1021/ja808853q • Publication Date (Web): 24 December 2008

Downloaded from http://pubs.acs.org on February 11, 2009

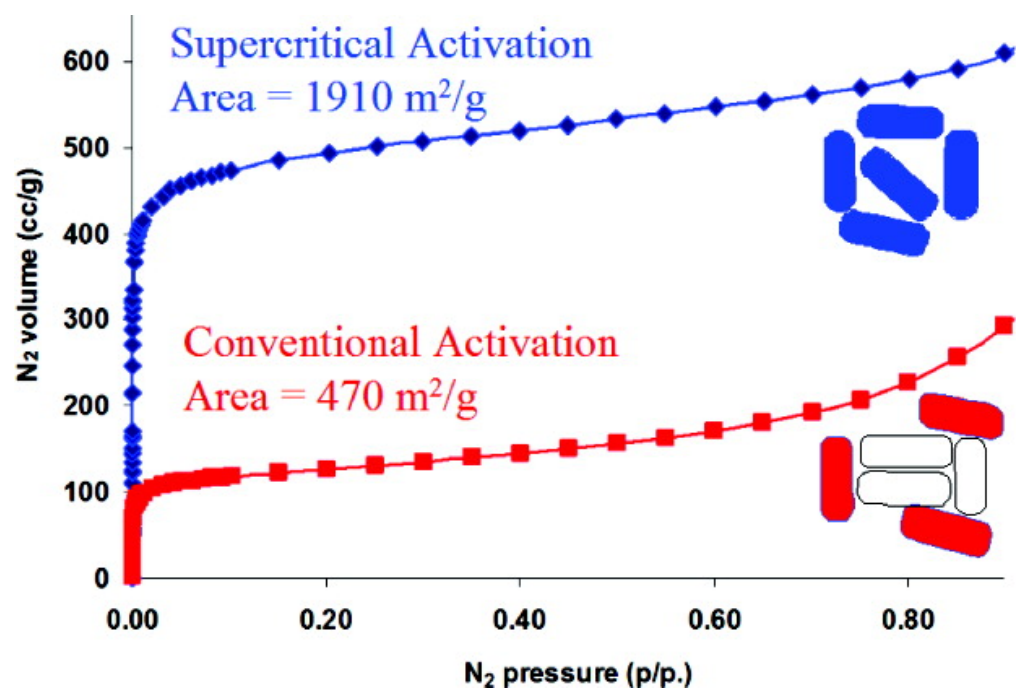

\section{More About This Article}

Additional resources and features associated with this article are available within the HTML version:

- Supporting Information

- Access to high resolution figures

- $\quad$ Links to articles and content related to this article

- Copyright permission to reproduce figures and/or text from this article

\section{View the Full Text HTML}




\title{
Supercritical Processing as a Route to High Internal Surface Areas and Permanent Microporosity in Metal-Organic Framework Materials
}

\author{
Andrew P. Nelson, ${ }^{\dagger, \S}$ Omar K. Farha, ${ }^{\dagger}$ Karen L. Mulfort, ${ }^{\dagger, \ddagger}$ and Joseph T. Hupp ${ }^{*, \dagger}$ \\ Department of Chemistry and International Institute for Nanotechnology, Northwestern University, 2145 Sheridan \\ Road, Evanston, Illinois 60208, and Division of Chemical Sciences and Engineering, Argonne National Laboratory, \\ Argonne, Illinois 60439
}

Received November 11, 2008; E-mail: j-hupp@northwestern.edu

Crystalline metal-organic frameworks $(\mathrm{MOFs})^{1}$ have emerged as attractive materials for a remarkably wide range of potential applications, including chemical separations, ${ }^{2}$ size-selective molecular catalysis, ${ }^{3}$ and chemical fuel storage and release. ${ }^{4}$ Among the materials properties favoring these particular applications are permanent microporosity and large internal surface areas. Unfortunately, the surface areas attained experimentally are often less than anticipated from computational studies or single-crystal X-ray structural studies. ${ }^{5}$ Furthermore, they can differ substantially from laboratory to laboratory. The dispartities and discrepancies have most often been attributed to channel collapse upon solvent removal or channel blockage due to solvent retention. ${ }^{6}$ In many instances, porosity can be recovered and surface areas can be increased by exchanging the MOF-incorporated solvent remaining from synthesis for a lower boiling point solvent and then removing the solvent under relatively mild conditions. ${ }^{7}$ Nevertheless, in our experience, and presumably that of others, the liquid solvent exchange strategy still occasionally fails to elicit MOF microporosity or, more commonly, succeeds in enabling access to the internal surface area of a given MOF, but to a lesser extent than anticipated from computations.

Here we report on a very promising alternative approach entailing processing of solvent-containing MOF materials with liquid and supercritical carbon dioxide. To illustrate, we report the behavior of two new MOFs as well as two previously described materials. In all four cases the materials comprise dicarboxylated organic ligands as struts and $\mathrm{Zn}$ (II)-containing clusters as nodes. As shown below, the new approach is capable of very substantially enhancing access to MOF internal surface area, relative to treatments entailing either (a) thermally assisted evacuation of the solvent used for synthesis (DMF or DEF) ("conventional activation") or (b) liquid solvent exchange (e.g., DMF $\Leftrightarrow \mathrm{CHCl}_{3}$; DEF $\Leftrightarrow \mathrm{THF}$ ) followed by pore evacuation at moderate temperature (DMF $=$ dimethylformamide, $\mathrm{DEF}=$ diethylformamide, $\mathrm{THF}=$ tetrahydrofuran).

As detailed in the Supporting Information (SI), the first of the four investigated materials was obtained by solvothermal synthesis from a DEF solution of $\mathrm{ZnNO}_{3} \cdot 6 \mathrm{H}_{2} \mathrm{O}$ and a napthalenediimidecontaining ligand, $\mathbf{1}$. Figure 1 shows several views of the resulting channel-containing material, 5. ${ }^{8}$ The nodes of 5 consist of $\mathrm{Zn}_{4} \mathrm{O}$ clusters, coordinated by carboxylates in both a mono- and bidentate fashion. Each node is also coordinated by one water and two DEF molecules. In contrast to the cubic frameworks typically obtained with these clusters, the unusual coordination produces a canted rhombohedral framework. The single-crystal X-ray structure indi-

\footnotetext{
Northwestern University.

* Argonne National Laboratory.

$\$$ Present address: Synthesis and Formulations Branch, Naval Air Warfare Center, Weapons Division, China Lake, California 93555.
}

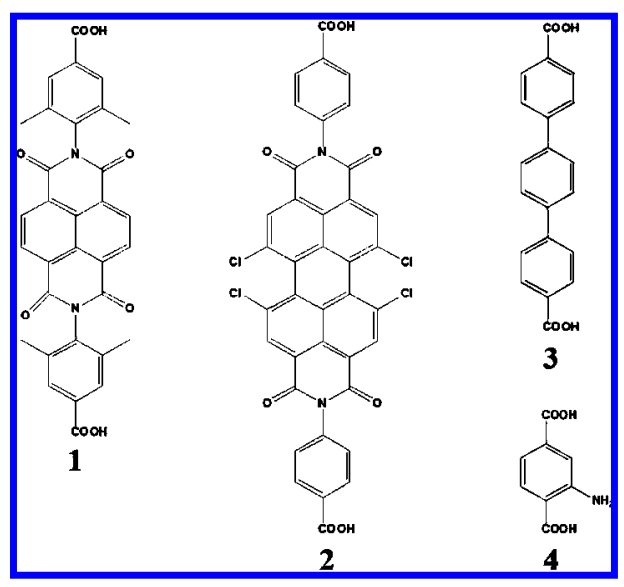

cates, as expected, that the channels of "as-synthesized" $\mathbf{5}$ are fully occupied, presumably by disordered DEF.

A similar solvothermal synthesis in DMF, but with ligand 2 rather than 1, yielded a red solid, $\mathbf{6}$. While we were unable to obtain a suitable single crystal for X-ray structural determination, powder $\mathrm{X}$-ray diffraction (PXRD) measurements revealed that the material is crystalline (see SI). ${ }^{1} \mathrm{H}$ NMR measurements of a sample of 6 that had been thermally evacuated and then dissolved in $\mathrm{D}_{2} \mathrm{SO}_{4}$ showed the presence only of $\mathbf{2}$ and a trace amount of DMF.

Thermal gravimetric analysis (TGA) of $\mathbf{5}$ indicated a ca. $35 \%$ mass decrease (solvent loss) upon heating to $250{ }^{\circ} \mathrm{C}$ (see SI), a

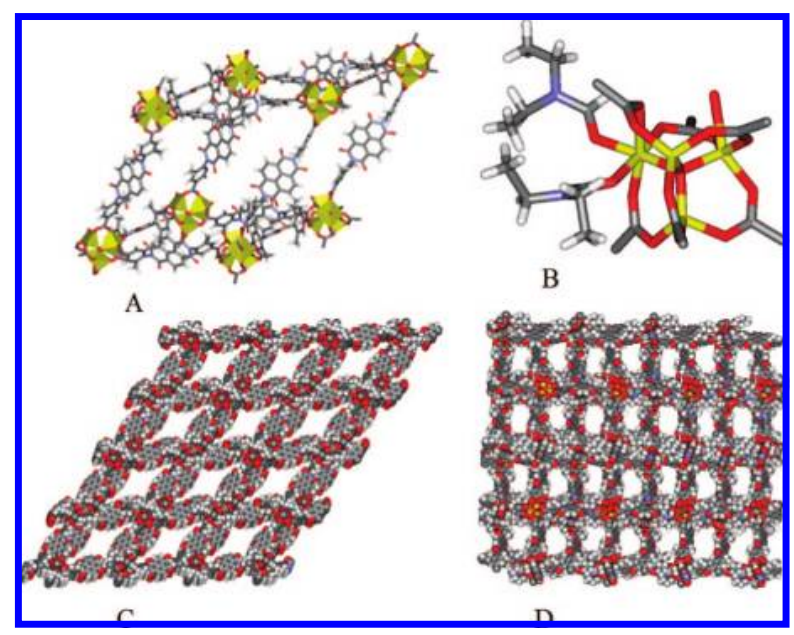

Figure 1. Crystallographically derived: (A) structure of 5, (B) corner cluster, showing coordination modes of $\mathbf{1}$ and two DEF molecules, (C) $a c$ plane of 5, looking down $b$-channels, and (D) $a b$-plane of 5, looking down $c$-channels. For clarity, disordered DEF molecules are omitted from images A, C, and D. For image A, coordinated DEF molecules are also omitted. 


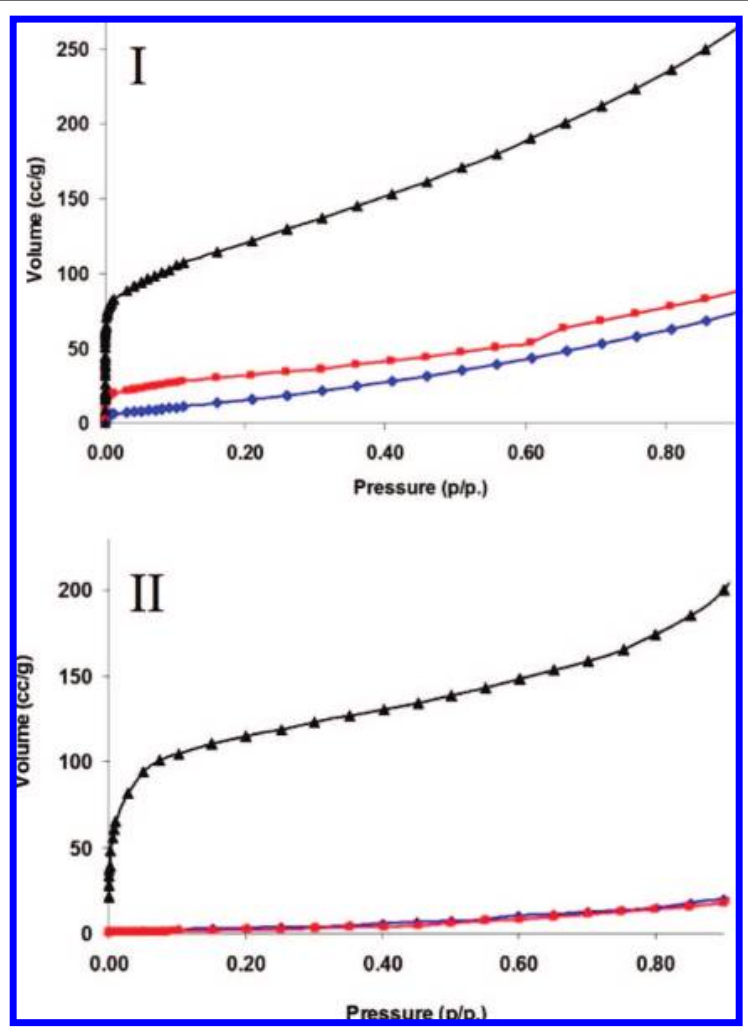

Figure 2. (I) $77 \mathrm{~K} \mathrm{~N} \mathrm{~N}_{2}$ adsorption isotherms of $\mathbf{5}$ following ScD activation (top), exchange with THF and evacuation at $25^{\circ} \mathrm{C}$ (middle), or conventional activation at $110{ }^{\circ} \mathrm{C}$ (bottom). (II) $77 \mathrm{~K} \mathrm{~N}_{2}$ isotherms of 6 following $\mathrm{ScD}$ activation (top), exchange with chloroform, followed by evacuation at 25 ${ }^{\circ} \mathrm{C}$ (bottom, red), or traditional activation $110{ }^{\circ} \mathrm{C}$ (bottom, blue (overlap)).

Table 1. Nitrogen-Accessible Surface Areas $\left(\mathrm{m}^{2} / \mathrm{g}\right)$ of Various Framework Materials as a Function of Method of Pore Evacuation

\begin{tabular}{lccr}
\hline material & $\begin{array}{c}\text { conventional } \\
\text { thermal } \\
\text { evacuation }\end{array}$ & $\begin{array}{c}\mathrm{CHCl}_{3} \text { or } \\
\mathrm{THF} \\
\text { exchange }\end{array}$ & $\mathrm{ScD}$ \\
\hline IRMOF-3 & 10 & 1800 & 2850 \\
IRMOF-16 & na & 470 & 1910 \\
$\mathbf{5}$ & 5 & 135 & 400 \\
$\mathbf{6}$ & 5 & 36 & 430 \\
\hline
\end{tabular}

result consistent with the porosity implied by the X-ray structure and suggesting substantial internal surface area. TGA measurements of 6 showed a $17 \%$ mass loss upon heating to $300{ }^{\circ} \mathrm{C}$ (see SI; the framework itself is stable to ca. $400{ }^{\circ} \mathrm{C}$ ). The diminished solvent capacity despite the larger strut size is suggestive of network catenation, the formation of a 2D rather than 3D structure, or both.

In contrast to the implications from X-ray and/or TGA measurements, $\mathrm{N}_{2}$ adsorption studies $(77 \mathrm{~K}$ ) indicate negligible accessible surface areas for either $\mathbf{5}$ or $\mathbf{6}$, following conventional thermal activation (Figure 2 and Table 1). Solvent exchange with $\mathbf{6}\left(\mathrm{CHCl}_{3}\right)$ yields no meaningful improvement, while solvent exchange with 5 (THF) yields a modest Brunauer-Emmet-Teller (BET) surface area of $135 \mathrm{~m}^{2} / \mathrm{g}$.

Confronted with these disappointing results, we turned to supercritical drying $(\mathrm{ScD})$ as a potential activation method. $\mathrm{ScD}$ has been used previously in polymer synthesis and preparation of organosilicates and high-area silica aerogels. ${ }^{9}$ Additionally, the low cost of $\mathrm{CO}_{2}(\mathrm{~g})$ and the dryer make this a practical method. Briefly, the solvent remaining from MOF synthesis was first exchanged with $\mathrm{EtOH}$ (miscible with $\mathrm{CO}_{2}$ and compatible with our instrument) and

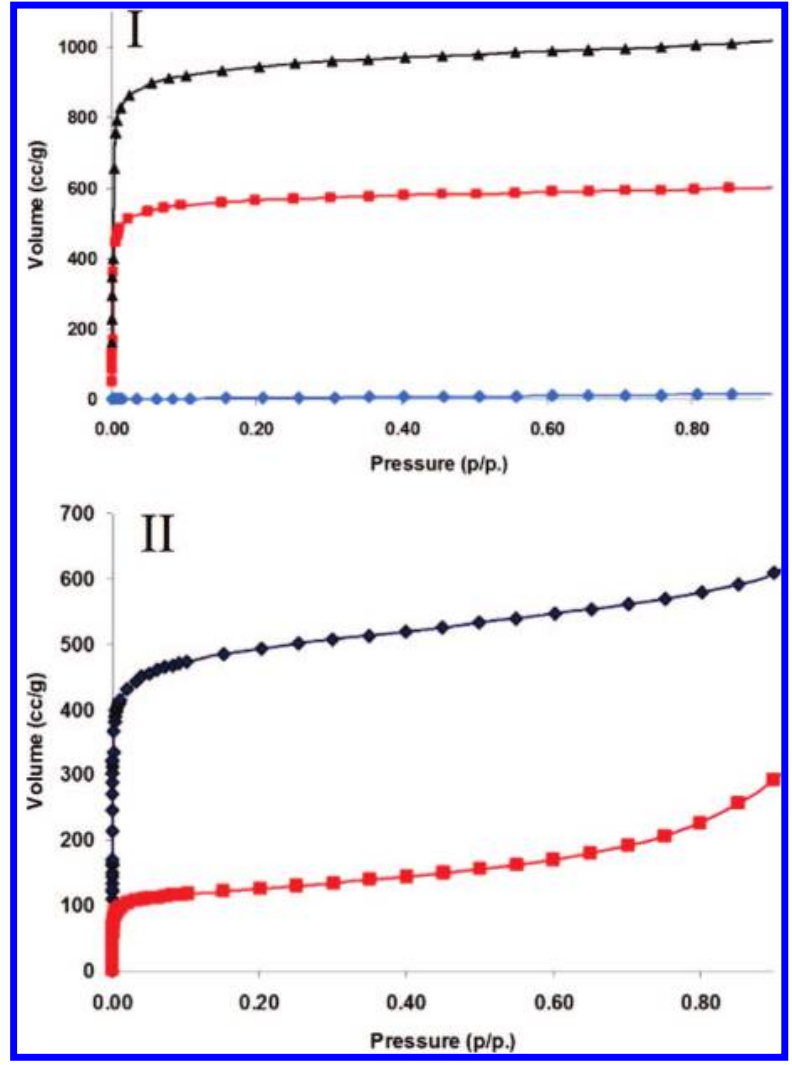

Figure 3. ( I) $77 \mathrm{~K} \mathrm{~N}_{2}$ isotherms of IRMOF-3 following ScD activation (top), exchange with $\mathrm{CHCl}_{3}$ followed by evacuation at $25^{\circ} \mathrm{C}$ (middle), or conventional activation at $100{ }^{\circ} \mathrm{C}$ (bottom). (II) $77 \mathrm{~K} \mathrm{~N}$ isotherms of IRMOF-16 following $\mathrm{ScD}$ activation (top) or exchange with $\mathrm{CHCl}_{3}$ followed by activation at $25{ }^{\circ} \mathrm{C}$ (bottom).

then with liquid $\mathrm{CO}_{2}$. The sample was then taken above the carbon dioxide critical point $\left(T=31{ }^{\circ} \mathrm{C} ; P=73 \mathrm{~atm}\right)$, held for $30 \mathrm{~min}$, and finally, slowly vented (18 h; further details in SI). As illustrated in Figure 2, the results are striking: the $\mathrm{N}_{2}$-accessible surface area increases to $400 \mathrm{~m}^{2} / \mathrm{g}$ for 5 (3-fold increase) and $430 \mathrm{~m}^{2} / \mathrm{g}$ for $\mathbf{6}$ (12-fold increase).

With these results in hand, we extended the investigation to noncatenated, cubic, "isoreticular" MOFs constructed from ligands 4 (IRMOF-3) and 3 (IRMOF-16). ${ }^{7,10}$ IRMOF-3 has attracted considerable recent attention because of its susceptibility to postsynthetic covalent modification via the available amine group. ${ }^{11}$ For IRMOF-3, activation via solvent exchange (DMF $\Leftrightarrow \mathrm{CHCl}_{3}$ ) yielded a surface area of $1800 \mathrm{~m}^{2} / \mathrm{g}$. ScD activation increases the $\mathrm{N}_{2}$ accessible surface area to $2850 \mathrm{~m}^{2} / \mathrm{g}$ (Figure 3). For IRMOF16 there are, to our knowledge, no previous reports of surface area. From Figure 3, we observe that activation of IRMOF-16 via solvent exchange yields a $\mathrm{N}_{2}$-accessible surface area of $470 \mathrm{~m}^{2} / \mathrm{g}$ but that the surface area is quadrupled via $\mathrm{ScD}$ activation $\left(1910 \mathrm{~m}^{2} / \mathrm{g}\right)$.

We hypothesize that the key feature of supercritical activation is the elimination of solvent $\left(\mathrm{CO}_{2}\right)$ surface tension at temperatures and pressures above the critical point. For aerogel fabrication, the elimination of surface tension, and therefore capillary forces, prevents the pore collapse that would otherwise occur upon removal of solvent. ${ }^{9}$ In contrast, because of their tiny size and the relative strength of the zinc-oxygen bonds that define them, the crystalline micropores that permeate the four MOFs should be resistant to collapse via capillary effects, even with solvents such as DEF and DMF. The persistence of crystallinity in solvent-exchanged $\mathbf{6}$, despite its inability to adsorb nitrogen, supports this contention. Similarly, the ability to resolvate 6 with DMF after nitrogen 


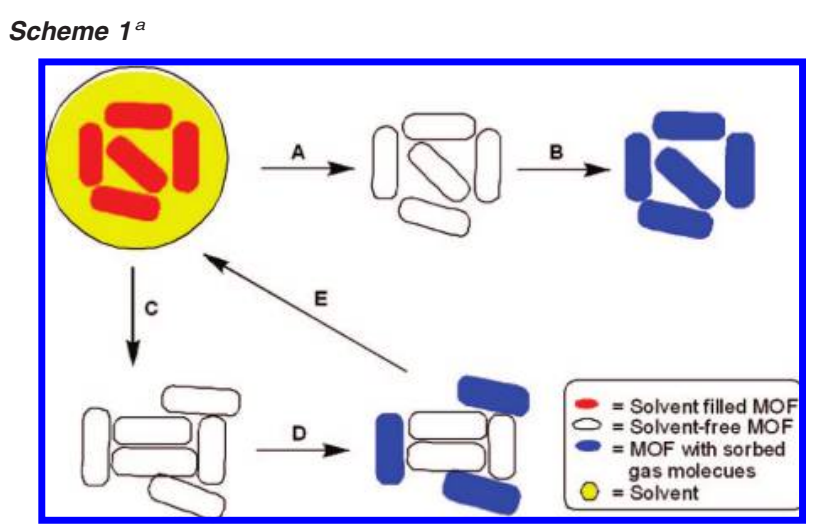

${ }^{a}$ (A) Supercritical $\mathrm{CO}_{2}$ activation of MOF microcrystals, (B) adsorption of gas molecules after supercritical $\mathrm{CO}_{2}$ activation, (C) traditional activation of MOF crystals, (D) adsorption of gas molecules after traditional activation, and $(\mathrm{E})$ resolvation.

adsorption isotherms (TGA experiments; see SI), indicates preservation of micropores in nitrogen-impermeable samples. Similar behavior is seen for other MOFs. Thus, collapse of crystallographically defined channels appears not to be the primary cause of surface-area loss in the four MOFs examined (although it may be a secondary contributor).

As illustrated in Scheme 1, we hypothesize that thermal evacuation of solvent instead causes the collapse of interparticle mesopores. Misalignment of micropores at particle/particle boundaries then inhibits access by gas molecules to internal (microporous) surfaces. At the same time, re-exposure to liquid solvent should enable particles to separate and to take up comparatively large solvent molecules (as is indeed observed). In contrast, $\mathrm{ScD}$ activation prevents mesopore collapse, leaving micropores accessible to gas molecules. Consistent with this description, we find that thermally evacuated samples of $\mathbf{5}$, exhibiting negligible surface area, can be rendered microporous by resolvating the material and then subjecting it to $\mathrm{ScD}$ (steps $\mathrm{E} \rightarrow \mathrm{A} \rightarrow \mathrm{B}$ in Scheme 1; final surface area $\left.=370 \mathrm{~m}^{2} / \mathrm{g}\right)$ ).

To summarize, careful processing of four representative MOFs with liquid and supercritical carbon dioxide leads to substantial, or in some cases spectacular (up to $1200 \%$ ), increases in gas-accessible surface area. Maximization of surface area is key to the optimization of MOFs for many potential applications. Preliminary evidence points to inhibition of mesopore collapse, and therefore micropore accessibility, as the basis for the extraordinarily efficacious outcome of ScD-based activation.

Acknowledgment. We gratefully acknowledge the U.S. Dept. of Energy, Office of Science, Basic Energy Science Program (Grant no. DE-FG02-08-ER15967) and the Northwestern Nanoscale Science and Engineering Center for financial support. A.P.N. thanks the ACS Petroleum Research Fund for an Alternative Energy
Postdoctoral Fellowship. K.L.M. thanks Argonne National Laboratory for a Laboratory-Grad Fellowship.

Supporting Information Available: Experimental procedures for the synthesis of $\mathbf{1}, \mathbf{2}, \mathbf{3}, \mathbf{5}$, and $\mathbf{6}$. X-ray crystallographic files for $\mathbf{5}$ in CIF format. PXRD, TGA, and sorption isotherm data. ${ }^{1} \mathrm{H}$ NMR data on residual solvent content of $\mathbf{3}$ as a function of activation method. This material is available free of charge via the Internet at http:// pubs.acs.org.

\section{References}

(1) Recent reviews: (a) Collins, D. J.; Zhou, H.-C. J. Mater. Chem. 2007, 17, 3154-3160. (b) Férey, G. Chem. Soc. Rev. 2008, 37, 191-214.

(2) For example, see: (a) Bastin, L.; Barcia, P. S.; Hurtado, E. J.; Silva, J. A. C.; Rodrigues, A. E.; Chen, B. J. Phys. Chem. C 2008, 112, 1575-1581. (b) Lee, E. Y.; Jang, S. Y.; Suh, M. P. J. Am. Chem. Soc. 2005, 127, 63746381. (c) Dinca, M.; Long, J. R. J. Am. Chem. Soc. 2005, 127, 93769377. (d) Snurr, R. Q.; Hupp, J. T.; Nguyen, S. T. AIChE 2004, 50, 10901095. (e) Bae, Y. S.; Mulfort, K. L.; Frost, H.; Ryan, P.; Punnathanam, S.; Broadbelt, L. J.; Hupp, J. T.; Snurr, R. Q. Langmuir 2008, 24, 8592-8598. (f) Bae, Y. S.; Farha, O. K.; Spokoyny, A. M.; Mirkin, C. A.; Hupp, J. T.; Snurr, R. Q. Chem. Commun. 2008, 4135-4137.

(3) (a) Wu, C.-D.; Hu, A.; Zhang, L.; Lin, W. J. Am. Chem. Soc. 2005, 127, 8940-8941. (b) Horike, S.; Dinca, M.; Tamaki, K.; Long, J. R. J. Am. Chem. Soc. 2008, 130, 5854-5855. (c) Cho, S.-H.; Ma, B.; Nguyen, S. T.; Hupp, J. T.; Albrecht-Schmitt, T. E. Chem. Commun. 2006, 256, 3-2565.

(4) For example, see: (a) Collins, D. J.; Zhou, H.-C. J. Mater. Chem. 2007, 17,3154-3160. (b) Férey, G. Chem. Soc. Rev. 2008, 37, 191-214. (c) Nouar, F.; Eubank, J. F.; Bousquet, T.; Wojtas, L.; Zaworotko, M. J.; Eddaoudi, M. J. Am. Chem. Soc. 2008, 130, 1833-1835. (d) Chen, B.; Ockwig, N. W.; Millard, A. R.; Contreras, D. S.; Yaghi, O. M. Angew. Chem., Int. Ed. 2005, 44, 4745-4749. (e) Dinca, M.; Dailly, A.; Liu, Y.; Brown, C. M.; Neumann, D. A.; Long, J. R. J. Am. Chem. Soc. 2006, 128, 16876-16883. (f) Latroche, M.; Surblé, S.; Serre, C.; Mellot-Draznieks, C.; Llewellyn, P. L.; Lee, H.; Chang, J.; Jhung, S. H.; Férey, G. Angew. Chem., Int. Ed. 2006, 45, 8227-8231. (g) Mulfort, K. L.; Hupp, J. T. J. Am. Chem. Soc. 2007, 129, 9604-9605. (h) Farha, O. K.; Spokoyny, A. M.; Mulfort, K. L.; Hawthorne, M. F.; Mirkin, C. A.; Hupp, J. T. J. Am. Chem. Soc. 2007, 129, 12680-12680.

(5) Duren, T.; Milliange, F.; Ferey, G.; Walton, K. S.; Snurr, R. Q. J. Phy. Chem. C 2007, 111, 15350-15356.

(6) (a) Kepert, C. J.; Rosseinsky, M. J. Chem. Commun. 1999, 375-376. (b) Yaghi, O. M.; Li, H.; Davis, C.; Richardson, D.; Groy, T. L. Acc. Chem. Res. 1998, 31, 474-484.

(7) Eddaoudi, M.; Kim, J.; Rosi, N.; Vodak, D.; Wachter, J.; O’Keeffe, M.; Yaghi, O. M. Science 2002, 295, 469-472.

(8) Inclusion of pairs of methyl groups on the phenyl carboxylate units proved essential for formation of a crystalline coordination polymer. Attempts to prepare MOFs using analogues of $\mathbf{1}$ lacking one or both methyl groups yielded only amorphous solids. As shown in the crystal structure of $\mathbf{5}$, the methyl groups render the napthelendiimide geometrically orthogonal to the phenyl carboxylate.

(9) (a) Reichenauer, G.; Scherer, G. W. Colloids Surf., A 2001, 187-188, 4150. (b) Reichenauer, G.; Scherer, G. W. J. Non-Cryst. Solids 2001, 285 , 167-174. (c) Cooper, A. I. J. Mater. Chem. 2000, 10, 207-234. (d) Lubguban, J. A.; Gangopadhyay, S.; Lahlouh, B.; Rajagopalan, T.; Biswas, N.; Sun, J.; Huang, D. H.; Simon, S. L.; Mallikarjunan, A.; Kim, H.-C.; Hedstrom, J.; Volksen, W.; Miller, R. D.; Toney, M. F. J. Mater. Res. 2004, 19, 3224-3233.

(10) IRMOF-16 was prepared by a method similar to that in the literature, ${ }^{7}$ but from DMF rather than DEF as solvent. Powder X-ray diffraction (PXRD) measurements confirm that IRMOF-16 is formed but do not rule out contamination with IRMOF-15 (the catenated analogue of IRMOF-16), as IRMOF-15 displays no unique PXRD peaks. IRMOF-15 contamination would be expected to produce falsely low surface areas for the IRMOF-16 sample.

(11) (a) Wang, Z.; Cohen, S. M. J. Am. Chem. Soc. 2007, 129, 12368-12369. (b) Wang, Z.; Cohen, S. M. Angew. Chem., Int. Ed. 2008, 47, 4699-4702. (c) Tanabe, K. K.; Wang, Z.; Cohen, S. M J.Am. Chem. Soc. 2008, 130, 8508-8517.

JA808853Q 